\title{
Extended steep ramp test normative values for 19-24-year-old healthy active young adults
}

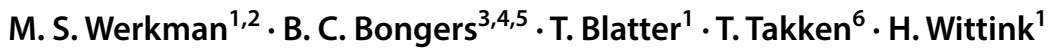

Received: 2 May 2019 / Accepted: 31 October 2019 / Published online: 8 November 2019

(c) The Author(s) 2019

\begin{abstract}
Purpose To extend currently available sex and age-specific normative values in children and adolescents for the peak work rate $\left(\mathrm{WR}_{\text {peak }}\right)$ attained at the steep ramp test (SRT) to healthy active young adults.

Methods Healthy male and female participants aged between 19 and 24 years were recruited. After screening and anthropometric measurements, participants performed a SRT on a cycle ergometer (increments of $25 \mathrm{~W} / 10 \mathrm{~s}$ ), monitoring and

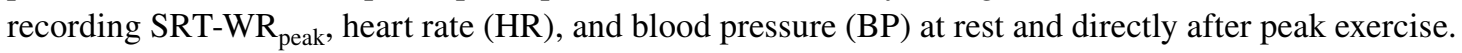

Results Fifty-seven participants ( 31 males and 26 females; median age of 21.3 years) volunteered and were tested. Anthropometrics, resting BP and lung function were all within normal ranges. Ninety-three percent of the participants attained a peak $\mathrm{HR}\left(\mathrm{HR}_{\text {peak }}\right)>80 \%$ of predicted (mean $\mathrm{HR}_{\text {peak }} 87 \pm 5 \%$ of predicted). No differences were found in resting and peak exercise variables between females and males, except for absolute SRT-WR peak $_{\text {( }}$ (350 W [Q1: 306; Q3: 371] and $487 \mathrm{~W}$ [Q1: 450; Q3: 517], respectively) and SRT-WR peak $_{\text {normalized for body mass (relative SRT-WR }}$ peak $; 5.4 \pm 0.5$ and $6.2 \pm 0.6 \mathrm{~W} /$ $\mathrm{kg}$, respectively). Low-to-moderate correlations $(\rho[0.02-0.71])$ were observed between SRT-WR $\mathrm{peak}_{\text {and }}$ anthropometric variables for females and males separately. Extended reference curves (8-24-year-old subjects) for SRT performance show different trends between male and female subjects when modelled against age, body height, and body mass.

Conclusions The present study provides sex-, age-, body height-, and body mass-related normative values (presented as reference centiles) for absolute and relative SRT performance throughout childhood and early adulthood.
\end{abstract}

Keywords Exercise testing $\cdot$ Field test $\cdot$ Cycle ergometry $\cdot$ Aerobic fitness $\cdot$ Cardiorespiratory fitness

\section{Abbreviations}

ACSM American College of Sports Medicine

BMI Body mass index

Communicated by Anni Vanhatalo.

Electronic supplementary material The online version of this article (https://doi.org/10.1007/s00421-019-04255-x) contains supplementary material, which is available to authorized users.

M. S. Werkman

m.s.werkman@lumc.nl

1 Research Group Lifestyle and Health, Research Center Healthy and Sustainable Living, University of Applied Sciences Utrecht, Utrecht, The Netherlands

2 Department of Physiotherapy, Leiden University Medical Center, Albinusdreef 2, 2333 ZA Leiden, The Netherlands

3 Department of Nutrition and Human Movement Sciences, School of Nutrition and Translational Research in Metabolism (NUTRIM), Faculty of Health, Medicine and Life Sciences, Maastricht University, Maastricht, The Netherlands
BP Blood pressure

BSA Body surface area

COPD Chronic obstructive pulmonary disease

CPET Cardiopulmonary exercise testing

CRF Cardiorespiratory fitness

ECG Electrocardiogram

$\mathrm{FEV}_{1} \quad$ Forced expiratory volume in one second
4 Department of Epidemiology, Care and Public Health Research Institute (CAPHRI), Faculty of Health, Medicine and Life Sciences, Maastricht University, Maastricht, The Netherlands

5 SOMT University of Physiotherapy, Amersfoort, The Netherlands

6 University Medical Center Utrecht, Wilhelmina Children's Hospital, Child Development and Exercise Center, Utrecht, The Netherlands 


\begin{tabular}{|c|c|}
\hline FM & Fat-free mass \\
\hline HR & Heart rate \\
\hline $\mathrm{ICC}_{2,1}$ & $\begin{array}{l}\text { Two-way random intra class correlation } \\
\text { coefficients }\end{array}$ \\
\hline LMS & Least-Mean-Square \\
\hline NA & Not applicable \\
\hline Q1 & 25th percentile \\
\hline Q3 & 75th percentile \\
\hline RER & Respiratory exchange ratio \\
\hline RPM & Revolutions per minute \\
\hline SD & Standard deviation \\
\hline SDC & Smallest detectable change \\
\hline SEE & Standard error of the estimate \\
\hline SEM & Standard error of measurement \\
\hline $\mathrm{SpO}_{2}$ & Peripheral oxygen saturation \\
\hline SPSS & Statistical Package for the Social Sciences \\
\hline SRT & Steep ramp test \\
\hline$V \mathrm{CO}_{2}$ & Carbon dioxide production \\
\hline VE & Minute ventilation \\
\hline$V \mathrm{O}_{2 \text { peak }}$ & Oxygen uptake at peak exercise \\
\hline $\mathrm{WR}_{\text {peak }}$ & Peak work rate \\
\hline$\%$ pred & Presented as percentage of predicted \\
\hline$\Delta \mathrm{BP}$ & Systolic BPpeak - systolic BPrest \\
\hline$\Delta \mathrm{HR}$ & HRpeak - HRrest \\
\hline
\end{tabular}

\section{Introduction}

Cardiopulmonary exercise testing (CPET) is a procedure involving an incremental, graded exercise test of 8-12 min in duration that provides essential diagnostic, prognostic, and evaluative information in a broad spectrum of (chronic) diseases (Vanhees et al. 2005). Traditionally, results from CPET are widely considered to be the criterion standard for measurement of cardiorespiratory fitness (CRF), reflected by the oxygen uptake at peak exercise $\left(V \mathrm{O}_{2 \text { peak }}\right)$ (Weisman et al. 2003).

Despite its clinical relevance, the use of formal CPET seems to be underused in current usual clinical practice. It has its (minor) disadvantages in the light of time investment, availability of the necessary equipment, and the required practical and theoretical skills of the laboratory staff (Stevens et al. 2010). Because of these limitations, there is a need for less sophisticated clinical exercise testing procedures to assess CRF that can easily be applied in usual care. Currently there are some alternatives of interest, such as the steep ramp test (SRT), which does not require respiratory gas analysis measurements.

The SRT has originally been developed as a short clinical exercise test to personalize and evaluate interval training in patients with heart failure (Meyer et al. 1996). The SRT is performed on a calibrated cycle ergometer up to volitional maximal exertion, and the attained peak work rate
$\left(\mathrm{SRT}-\mathrm{WR}_{\text {peak }}\right)$ is its primary outcome measure. Given its strong association with $V \mathrm{O}_{2 \text { peak }}$, SRT performance has been reported to provide a strong and reliable indication of CRF in different (patient) populations in the cardiopulmonary, metabolic, and oncological domains within a broad agerange (Bongers et al. 2015; Braam et al. 2015; De Backer et al. 2007; Rozenberg et al. 2015; Strookappe et al. 2016; Stuiver et al. 2017). Unfortunately, no such evidence about reliability and validity is available for healthy young adults.

Additionally, in healthy children and adolescents (Bongers et al. 2013a) and in adult cancer survivors (De Backer et al. 2007; Stuiver et al. 2017) and type II diabetes (Rozenberg et al. 2015) the SRT has recently been found to be a reliable and valid exercise test to predict $V \mathrm{O}_{2 \text { peak }}$ from the attained SRT-WR peak $_{\text {and }}$ anthropometric variables. However, these equations lack precision and induce large prediction margins for $V \mathrm{O}_{2 \text { peak }}$, which hampers their clinical usability for individuals (Stuiver et al. 2017). Moreover, predicting $V \mathrm{O}_{2 \text { peak }}$ from SRT performance is simply not necessary when adequate normative values for its primary outcome measure (SRT-WR $\mathrm{Weak}_{\text {) }}$ ) are available for a broad age-range.

Unfortunately, such normative values are only available for 8-19-year-old children and adolescents (Bongers et al. 2013b). Adequate normative values are of evident importance to track CRF in the young adult general health setting as it is for young adult patients with (chronic) diseases in which exercise testing and exercise training are part of usual care. Therefore, this study aimed to extend the currently available sex- and age-specific normative values for SRT performance in 19-24- year-old healthy active young adults.

\section{Methods}

\section{Design}

This study is part of the STEep Ramp test Norm values Utrecht Maastricht (STERNUM) study, which has been approved by the Medical Ethical Committee of the University Medical Center Utrecht (16-675/M). To extend the currently available normative values (Bongers et al. 2013b), this part of the study has been designed as an observational (crosssectional) study in which self-reported healthy active young adults participated. The range 19-24 years was chosen based on clinical considerations to provide extended norms for the same exercise test for follow-up of CRF during transition from the pediatric to the adult health care setting male and female participants without contra-indications (see "Measurements") for maximal exercise testing in the age between 19 and 24 years were recruited from the Utrecht University Campus region, dominantly at the Department of Movement Studies, University of Applied Sciences, Utrecht, The 
Netherlands. Informed consent was obtained from all individual participants included in the study. Participants were recruited and tested between March 2017 and November 2018. For statistical purposes, it was aimed to have a larger number of participants of 19 and 24 years of age.

All participants provided written informed consent and all procedures performed in studies involving human participants were in accordance with the ethical standards of the institutional and/or national research committee (Medical Ethical Committee of the University Medical Center Utrecht) and with the 1964 Helsinki Declaration and its later amendments or comparable ethical standards. The data sets generated during and/or analyzed during the current study are available from the corresponding author on reasonable request.

\section{Measurements}

Participants were recruited using flyers and defined themselves as healthy and compliant with the Dutch Physical Activity Guidelines (Weggemans et al. 2018). Before testing procedures, participants were screened for eligibility by administrating the American College of Sports Medicine (ACSM) preparticipation screening questionnaire, including questions about medical history (e.g., presence of known cardiovascular, pulmonary, neurological, or musculoskeletal disease), exercise-related complaints, and cardiovascular risk factors (Balady et al. 1998). Additionally, an anamnesis, blood cholesterol level measurement, resting supine electrocardiogram, and resting supine blood pressure were taken to confirm the outcome of the preparticipation questionnaire. Furthermore, pulmonary function was tested to confirm statements in the questionnaire, as well as to exclude the possibility of a ventilatory constraint-limiting exercise performance. Contra-indications for maximal exercise testing as described in the American Thoracic Society/American College of Chest Physicians Statement on Cardiopulmonary Exercise Testing were asked for in the anamnesis (ATS/ACCP 2003). "Healthy" was then operationalized as the combination of the following items: (1) self-reported healthy, without complaints during physical activity or exercise, (2) self-reported and anamnesis-based absence of contra-indications for maximal exercise, (3) self-reported non-smoking, and (4) normal pulmonary function and normal blood pressure (BP) and electrocardiogram (ECG) at rest and during exercise. All procedures and tests were performed by two trained and experienced clinical exercise physiologists (TB and MW). When no contraindications were identified, the formal testing procedure continued.

Before exercise testing, each participant's body height and body mass were measured. Body mass index [BMI ( $\mathrm{kg} /$ $\mathrm{m}^{2}$ )] was calculated as the body mass divided by body height squared. Body surface area [BSA $\left(\mathrm{m}^{2}\right)$ ] was estimated using the equation of Haycock et al. (1978). Skinfold thickness was measured at the right side triceps, biceps, subscapular, and suprailiacal site with a Harpenden skinfold caliper (Baty International, West Sussex, United Kingdom). Subcutaneous fat as a percentage of body mass was then calculated out of the four-site sum of skinfolds (Durnin and Womersley 1974), where after fat-free mass (FFM) was calculated. Lung function, operationalized as the forced expiratory volume in 1 second $\left(\mathrm{FEV}_{1}\right)$ measured in $\mathrm{L}$ and expressed as a percentage of predicted (Quanjer et al. 1993), was measured while sitting upright on the cycle ergometer. Participants performed three maximal flow-volume maneuvers through a face mask (Hans Rudolph Inc., Kansas City, MO, USA) that was connected to a calibrated metabolic cart (MetaLyzer 3BR2, Cortex Biophysik GmbH, Leipzig, Germany) with software (MetaSoft Studio v5.8.5 SR2, Cortex Biophysik GmbH, Leipzig, Germany).

The SRT was performed according to a previously published procedure in adult patients with heart failure (Meyer et al. 1996). Cycling was performed on an electronically braked cycle ergometer (Lode Corival, Lode BV, Groningen, The Netherlands). Heart rate (HR) was monitored continuously using a 12-lead ECG (Custocor Custo Med, Ottobrunn, Germany). Blood pressure (BP) was monitored at rest and directly after exercise cessation using the Riva Rocci method, without duplication or triplication of the measurement due to pragmatic reasons (Maxistabil 3 sphygmo manometer, Heine Adult-cuff, Speidel \& Keller, Jungingen, Germany). Each participant was carefully instructed about the testing procedure, including information about the importance to perform a true maximal effort and how to handle in the case of any possible complaints. Participants were already familiar with the SRT procedure as it is part of the standard pallet of exercise tests taught in the first study year. Afterwards, the participant was fitted with all equipment. After assessment of baseline HR and BP during a three-minute resting period while seated on the cycle ergometer, the test started with 2 min of unloaded cycling. Thereafter, work rate was linearly increased by a ramp protocol equaling $25 \mathrm{~W}$ each $10 \mathrm{~s}$. Participants were instructed to maintain a pedaling rate between 60 and 80 revolutions per minute. Strong verbal encouragement was given by the investigators until the participant terminated the SRT because of voluntary exhaustion or when their pedaling frequency fell definitely $<60$ revolutions per minute, despite strong verbal encouragement. The attained peak exercise values at the SRT $\left(\mathrm{WR}_{\text {peak }}, \mathrm{HR}_{\text {peak }}\right.$, and $\left.\mathrm{BP}_{\text {peak }}\right)$ and time until exhaustion (SRT duration in seconds, excluding the unloaded cycling phase) were recorded and the attainment of a maximal effort was noted in each participant's case report form. Performance was defined as maximal effort by the test leader when participants demonstrated subjective signs of exhaustion (e.g., unsteady biking, sweating, facial flushing, clear unwillingness to continue despite strong verbal encouragements). $\mathrm{HR}_{\text {peak }}$ was 
calculated and presented as percentage of predicted using the Nes formula (Predicted $\mathrm{HR}_{\text {peak }}=211-(0.64 \times$ age $\left.)\right)($ Nes et al. 2013).

\section{Data analysis}

Data analysis concerning anthropometrics, male-female differences and associations between parameters has been focused on the current 19-24-year-old group. Data analysis was performed with the Statistical Package for the Social Sciences (SPSS version 25, IBM SPSS Inc, Chicago, Illinois). All data are expressed as mean \pm standard deviation (SD) and [range] or as median [Q1; Q3] when not normally distributed. Normality of the data was tested with the Kolmogorov-Smirnov test. Differences between males and females were examined with independent sample t-tests, or Mann-Whitney $U$ test as appropriate. To counteract the possible problem of multiple comparisons the Bonferroni method was performed $(0.05 / k=16$ comparisons). Pearson $(r)$ or Spearman $(\rho)$ correlation coefficients were calculated to examine associations

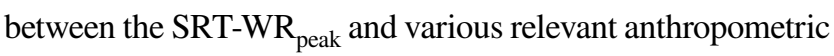
variables. The raw data previously collected in 8- to 19-yearold males and females by Bongers et al. (Bongers et al. 2013b) were combined with the current 19-24-year-old raw data set to develop sex-, age-, body height-, and body mass-specific normative values for 8-24-year-old males and females. Refer-

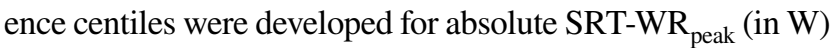
and body mass- and FFM-corrected "relative" SRT-WR peak (in W/kg and W/kg FFM, respectively) and variables were plotted against age, body height, and body mass. The LambdaMu-Sigma (LMS) Chart Maker Pro version 2.3 software (The Institute of Child Health, London, UK) was used, which fits smooth centile curves to reference data (Cole and Green 1992). According to our statistical expert there is no formal possibility to perform a power calculation for setting up norm values using the LMS method. Similar to the previous Bongers study (Bongers et al. 2013b), participants were stratified in 1-year clusters stratified on sex and age. Obviously, in that study a larger $(n=252)$, but also a population wider in age range (8-19) was included. As such, growth and maturation did play a much more dominant role in the development of reference curves in that pediatric and adolescent group than expected in the current young adult group. Therefore, our sample of 70 healthy young adults seems to be a feasible and sufficient number to construct generalizable norm values. A $p$ value $<0.05$ was considered statistically significant.

\section{Results}

Fifty-seven participants (31 males and 26 females; median age 21.3 years [Q1: 20.1; Q3: 23.4 years], range $19.1-24.9$ years) volunteered to participate in the study and were eligible to perform exercise testing after preparticipation screening. Of these, nine participants (16\%) had a right bundle branch block at the resting electrocardiogram, which was interpreted as no contraindication for maximal exercise testing by the consulting cardiologist. BMI, resting BP and lung function were all within normal ranges. As expected, males had higher values for body height, body mass, BSA, FFM, and absolute $\mathrm{FEV}_{1}$. Additionally, all participants were apparently healthy, non-smoking, and physically active [compliant to the Dutch Physical Activity Guidelines (Weggemans et al. 2018)] based on self-reported data and the administration of the ACSM screening questionnaire.

Most anthropometric, resting, and exercise variables, except age, body height, BSA, $\mathrm{FEV}_{1}$, resting systolic BP,

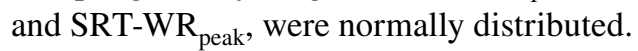

Participant characteristics and resting hemodynamic variables are presented in Tables 1 and 2. During and after exercise testing, only one (1.8\%) adverse event occurred (near syncope after maximal exercise), which recovered after several minutes in supine position. There were no events necessitating full 12-lead ECG control afterwards. All participants performed a maximal effort during the SRT, based on subjective signs of exhaustion or until pedal frequency fell definitely $<60 \mathrm{rpm}$, despite strong verbal encouragement. Peak exercise variables are presented in Table 2. Ninetythree percent of the participants attained a $\mathrm{HR}_{\text {peak }}>80 \%$ of predicted, with a mean $\mathrm{HR}_{\text {peak }}$ of $87 \pm 5 \%$ of predicted.

No differences were found in resting and peak exercise variables between females and males, except for absolute SRT-WR peak (350 W [Q1: 306; Q3: 371] and $487 \mathrm{~W}$ [Q1: 450; Q3: 517], respectively; $p<0.01)$, relative SRT-WR peak $(5.4 \pm 0.5$ and $6.2 \pm 0.6 \mathrm{~W} / \mathrm{kg}$, respectively; $p<0.01)$ and SRT duration (140 s [Q1: 122; Q3: 148] and $195 \mathrm{~s}$ [Q1: 180; Q3: 207], respectively; $p<0.01$ ). The hemodynamic response to maximal exercise at the SRT was comparable between females and males as reflected by comparable HR and BP values at peak exercise. Peak exercise variables are presented in Table 2.

Low-to-high correlations $(\rho[0.02-0.71])$ were observed between absolute SRT-WR $\mathrm{R}_{\text {peak }}$ and various anthropometric variables, as shown in Table 3 for females and males separately. As expected, absolute SRT-WR peak $_{\text {was }}$ positively and statistically significant associated with body height, body mass, FFM, BSA, and $\mathrm{FEV}_{1}(\rho[0.46-0.71])$; all $p$ values $<0.017$ ). No significant correlation was observed between age and absolute SRT-WR peak $_{\text {in females and males }}$ $(\rho-0.33 ; p=0.10$ and $\rho 0.02 ; p=0.90$, respectively; see Table 3).

Figure 1 shows the age-specific reference centile charts

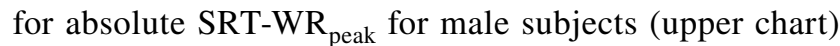
and female subjects (lower chart). In male subjects, the values demonstrate an almost linear increase in SRT-WR peak $_{\text {, }}$ until the age of approximately 15 years. After 15 years, 
Table 1 Participant characteristics

\begin{tabular}{llll}
\hline & $\begin{array}{l}\text { Females } \\
\text { Mean } \pm \text { SD [range]/median } \\
{[\mathrm{Q} 1 ; \mathrm{Q} 3]}\end{array}$ & $\begin{array}{l}\text { Males } \\
\text { Mean } \pm \text { SD [range]/median } \\
{[\mathrm{Q} 1 ; \mathrm{Q} 3]}\end{array}$ & $p(95 \% \mathrm{CI})^{*}$ \\
\hline Age $($ years $)$ & $21.0[19.8 ; 22.5]$ & $22.7[20.7 ; 23.8]$ & 0.02 \\
Body height $(\mathrm{cm})$ & $169.3[164.9 ; 177.4]$ & $186.0[183.6 ; 189.0]$ & $<0.01 * *$ \\
Body mass $(\mathrm{kg})$ & $63.7 \pm 7.3[49.0-81.0]$ & $77.0 \pm 9.1[47.0-99.0]$ & $<0.01[8.8 \text { to } 17.7]^{* *}$ \\
BMI $\left(\mathrm{kg} / \mathrm{m}^{2}\right)$ & $22.0 \pm 1.9[18.8-26.8]$ & $22.2 \pm 2.1[16.2-25.9]$ & $0.74[-0.9$ to 1.3$]$ \\
BSA & $1.7[1.7 ; 1.8]$ & $2.0[1.9 ; 2.1]$ & $<0.01^{* *}$ \\
FFM $(\mathrm{kg})$ & $47.1 \pm 5.7[37.4-57.8]$ & $68.4 \pm 7.8[44.4-80.0]$ & $<0.01^{* *}$ \\
$\mathrm{FEV}_{1}(\mathrm{~L})$ & $3.77[3.42 ; 3.90]$ & $5.17[4.80 ; 5.66]$ & $<0.01^{* *}$ \\
$\mathrm{FEV}_{1}(\% \mathrm{pred})$ & $104 \pm 11[86-128]$ & $104 \pm 10[82-121]$ & $0.91[-6$ to 5] \\
\hline
\end{tabular}

$B M I$ body mass index, $C I$ confidence interval, $F E V_{l}$ forced expiratory volume in one second, $F F M$ fat-free mass, $Q 1$ 25th percentile, Q3 75th percentile, \%pred presented as percentage of predicted $* 95 \% \mathrm{CI}$ only presented when tested parametrically

**Statistically significant after Bonferroni correction $(\alpha<0.003(0.05 / k=17)$

\begin{tabular}{|c|c|c|c|}
\hline & $\begin{array}{l}\text { Females } \\
\text { Mean } \pm \mathrm{SD} \text { [range]/ } \\
\text { median }[\mathrm{Q} 1 ; \mathrm{Q} 3]\end{array}$ & $\begin{array}{l}\text { Males } \\
\text { Mean } \pm \text { SD [range]/ } \\
\text { median [Q1; Q3] }\end{array}$ & $p(95 \% \mathrm{CI})^{*}$ \\
\hline \multicolumn{4}{|l|}{ Rest } \\
\hline HR (beats/min) & $82 \pm 13$ [55-104] & $80 \pm 11[60-103]$ & $0.58[-8$ to 5$]$ \\
\hline Systolic BP (mmHg) & $113[108 ; 128]$ & $118[111 ; 132]$ & 0.24 \\
\hline Diastolic BP (mmHg) & $72 \pm 9[49-84]$ & $72 \pm 10[41-89]$ & $0.90[-5$ to 6$]$ \\
\hline \multicolumn{4}{|l|}{ Peak exercise } \\
\hline $\mathrm{HR}_{\text {peak }}$ (beats/min) & $171 \pm 9[155-188]$ & $173 \pm 10[154-196]$ & $0.66[-4$ to 6$]$ \\
\hline $\operatorname{HR}_{\text {peak }}(\%$ pred $)$ & $87 \pm 5$ [79-95] & $88 \pm 5$ [79-99] & $0.51[-2$ to 3$]$ \\
\hline Systolic $\mathrm{BP}_{\text {peak }}(\mathrm{mm} \mathrm{Hg})$ & $165 \pm 17$ [129-193] & $171 \pm 20[134-221]$ & $0.24[-4$ to 17$]$ \\
\hline Diastolic BP (mm Hg) & $69 \pm 9[49-82]$ & $65 \pm 17[41-105]$ & $0.32[-11$ to 4$]$ \\
\hline SRT-WR peak $(\mathrm{W})$ & $350[306 ; 371]$ & $487[450 ; 517]$ & $<0.01 * *$ \\
\hline SRT-WR peak $(W / k g)$ & $5.4 \pm 0.5[4.0-6.2]$ & $6.2 \pm 0.6[4.5-7.6]$ & $<0.01[0.5 \text { to } 1.1]^{* *}$ \\
\hline SRT-WR peak $(\mathrm{W} / \mathrm{kg}$ FFM $)$ & $7.3 \pm 0.8[5.4-8.6]$ & $7.0 \pm 0.7[5.6-9.1]$ & $0.12[-0.69$ to 0.08$]$ \\
\hline SRT-duration (s) & $140[122 ; 148]$ & $195[180 ; 207]$ & $<0.01 * *$ \\
\hline
\end{tabular}

$B P$ blood pressure, $C I$ confidence interval, $F F M$ fat-free mass, $H R$ heart rate, $H R_{\text {peak }}$ peak heart rate, $Q 1$ 25th percentile, $Q 375$ th percentile, $s$ seconds, $S R T-W R_{\text {peak }}$ peak work rate attained at the steep ramp test, $\%$ pred presented as percentage of predicted

*95\% CI only presented when tested parametrically

**Statistically significant after Bonferroni correction $(\alpha<0.003(0.05 / k=18)$ the increase plateaus. In female subjects, the SRT-WR peak increased until the age of 19 years, where after it plateaus.

When normalized for body mass, Fig. 2 (upper chart) shows an almost linear increase of the relative SRT-WR $\mathrm{R}_{\text {peak }}$ in ages up to 19 years in male subjects, where after it stabilizes. In female subjects (lower chart), relative SRT$\mathrm{WR}_{\text {peak }}$ showed only a relatively small increase $(+0.6 \mathrm{~W} /$ $\mathrm{kg}$ ) until age 14 years, where after it plateaus until the age of 18 years. After 18 years, SRT-WR ${ }_{\text {peak }}$ shows a small increase $(+0.3 \mathrm{~W} / \mathrm{kg})$ again.

Additional Figures with body height- and body massrelated centile curves for the absolute $S R T-W_{\text {peak }}$ and

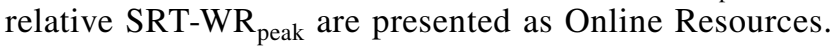

When absolute SRT-WR $\mathrm{Weak}_{\text {is }}$ plotted against body height (Online Resource 1), the upper chart (male subjects) shows an exponential increase in absolute SRT-WR $\mathrm{Weak}_{\text {until the }}$ body height of $155 \mathrm{~cm}$. When taller than $155 \mathrm{~cm}$, absolute SRT-WR peak seems to increase linearly with body height. In female subjects (lower chart), absolute SRT-WR peak $_{\text {seems to }}$ increase linearly from the body height of $145 \mathrm{~cm}$. In shorter female subjects, absolute SRT-WR peak seems to increase

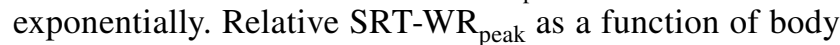
height (Online Resource 2), shows a wave-form trend for rel-

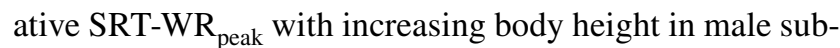
jects (upper chart). The lower bound of body height shows

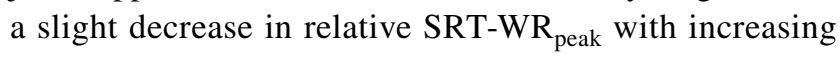


Table 3 Spearman Rank correlation coefficients for SRT-WR peak $_{\text {and }}$ selected anthropometric variables in 19- to 24-year old females and males

\begin{tabular}{|c|c|c|c|c|}
\hline \multirow[t]{2}{*}{ Variable } & \multicolumn{2}{|l|}{ Females } & \multicolumn{2}{|c|}{ Males } \\
\hline & $\rho$ & $p$ value & $\rho$ & $p$ value \\
\hline Age (years) & -0.33 & 0.10 & 0.02 & 0.90 \\
\hline Body mass (kg) & 0.54 & $<0.01 *$ & 0.61 & $<0.01 *$ \\
\hline Body height (cm) & 0.46 & $0.02 *$ & 0.55 & $0.01 *$ \\
\hline $\operatorname{BSA}\left(\mathrm{m}^{2}\right)$ & 0.53 & $0.01 *$ & 0.67 & $<0.01^{*}$ \\
\hline FFM $(\mathrm{kg})$ & 0.55 & $<0.01^{*}$ & 0.71 & $<0.01^{*}$ \\
\hline $\mathrm{FEV}_{1}(\mathrm{~L})$ & 0.47 & $0.02 *$ & 0.50 & $0.01 *$ \\
\hline
\end{tabular}

$B S A$ body surface area, $F E V_{I}$ forced expiratory volume in one second, FFM fat-free mass, $\rho$ Spearman rank correlation coefficient

*Statistically significant

body height up to $145 \mathrm{~cm}$. Thereafter, relative SRT-WR increases exponentially until $175 \mathrm{~cm}$, where after it starts to level off. In female subjects (lower chart), a stable relative SRT-WR ${ }_{\text {peak }}$ is observed throughout the entire body height range of $125-195 \mathrm{~cm}$ of approximately $5.0 \mathrm{~W} / \mathrm{kg}$.

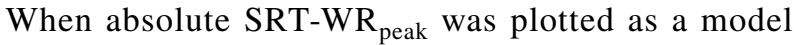
of body mass (Online Resource 3), the same trends were found for male subjects (upper chart) as in Online Resource 1 for body height. In female subjects, abso-

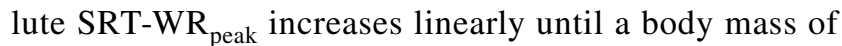
$60 \mathrm{~kg}$. Thereafter it starts to level off. The same optimum

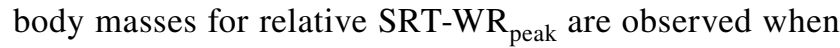
plotted against body mass (Online Resource 4). For both male subjects (upper chart) and female subjects (lower chart), relative peak performance occurred at a body mass of approximately $60 \mathrm{~kg}$. In male subjects a plateau remains until approximately $80 \mathrm{~kg}$, where after relative SRT-WR ${ }_{\text {peak }}$ starts to decrease. In female subjects, relative SRT-WR ${ }_{\text {peak }}$ directly starts to decrease after $60 \mathrm{~kg}$.

Figures were constructed based on the values in the tables in the Online Resource 5, presenting sex-, age-, body height-, body mass-, and FFM-related normative values for absolute and relative (normalized for body mass and FFM) SRT-WR ${ }_{\text {peak }}$ for 8-24-year-old males and females, expressed as centile scores (Online Resource 5).
Fig. 1 Age-related centile curves for the SRT-WR $\mathrm{Weak}_{\text {for }}$ male (upper charts) and female (lower charts) subjects. Bold solid lines represent the 50th centile (P50); dashed lines correspond to the 10th, 25th, 75th, and 90th centiles (P10, P25, $\mathrm{P} 75$, and $\mathrm{P} 90$, respectively); and solid lines indicate the $3 \mathrm{rd}$ and 97th centiles (P3 and P97, respectively)
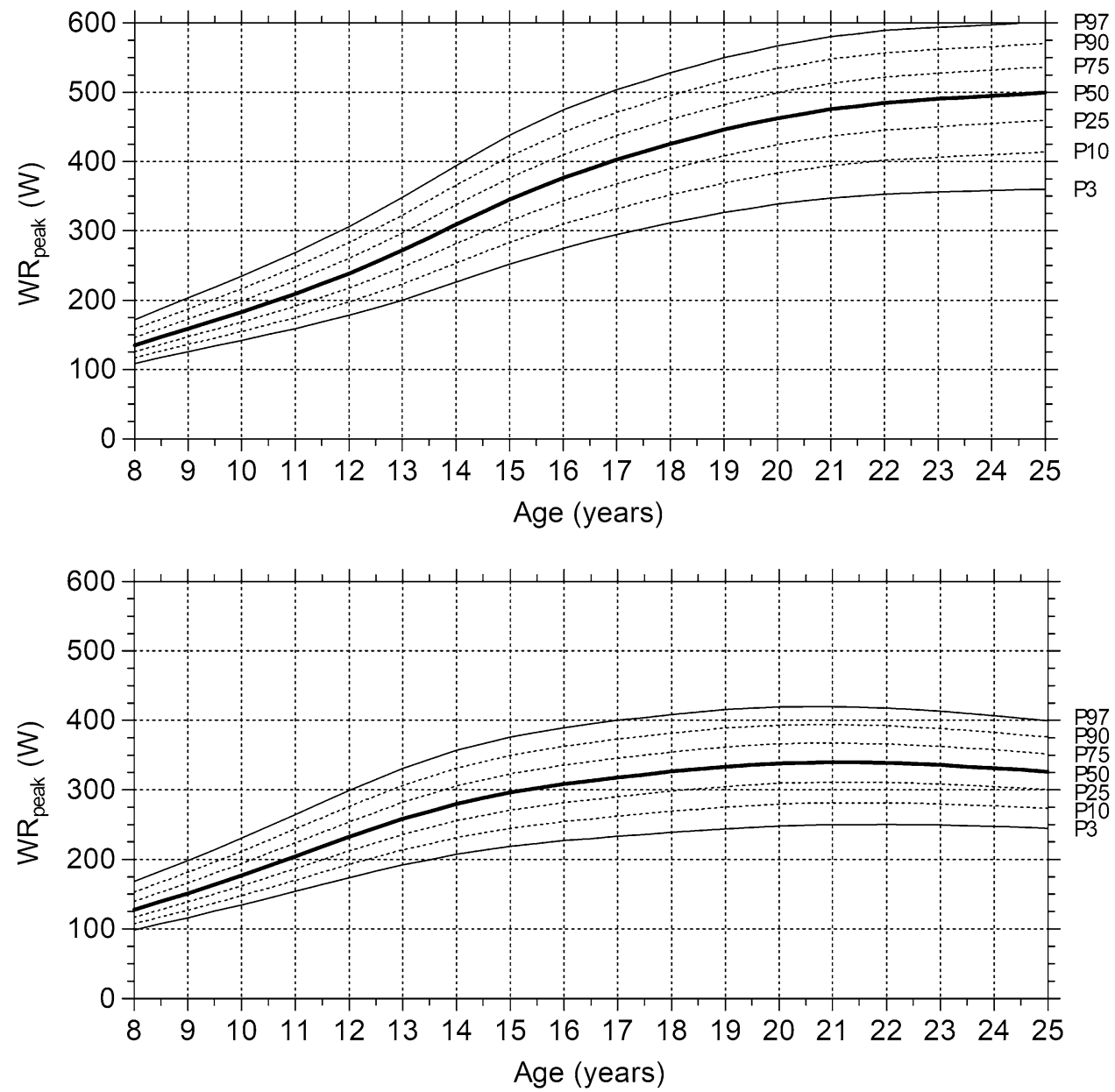
Fig. 2 Age-related centile curves for the Relative SRT$\mathrm{WR}_{\text {peak } / \mathrm{kg}}$ for male (upper charts) and female (lower charts) subjects. Bold solid lines represent the 50th centile (P50); dashed lines correspond to the 10th, 25th, 75th, and 90th centiles (P10, P25, P75, and $\mathrm{P} 90$, respectively); and solid lines indicate the $3 \mathrm{rd}$ and $97 \mathrm{th}$ centiles (P3 and P97, respectively)
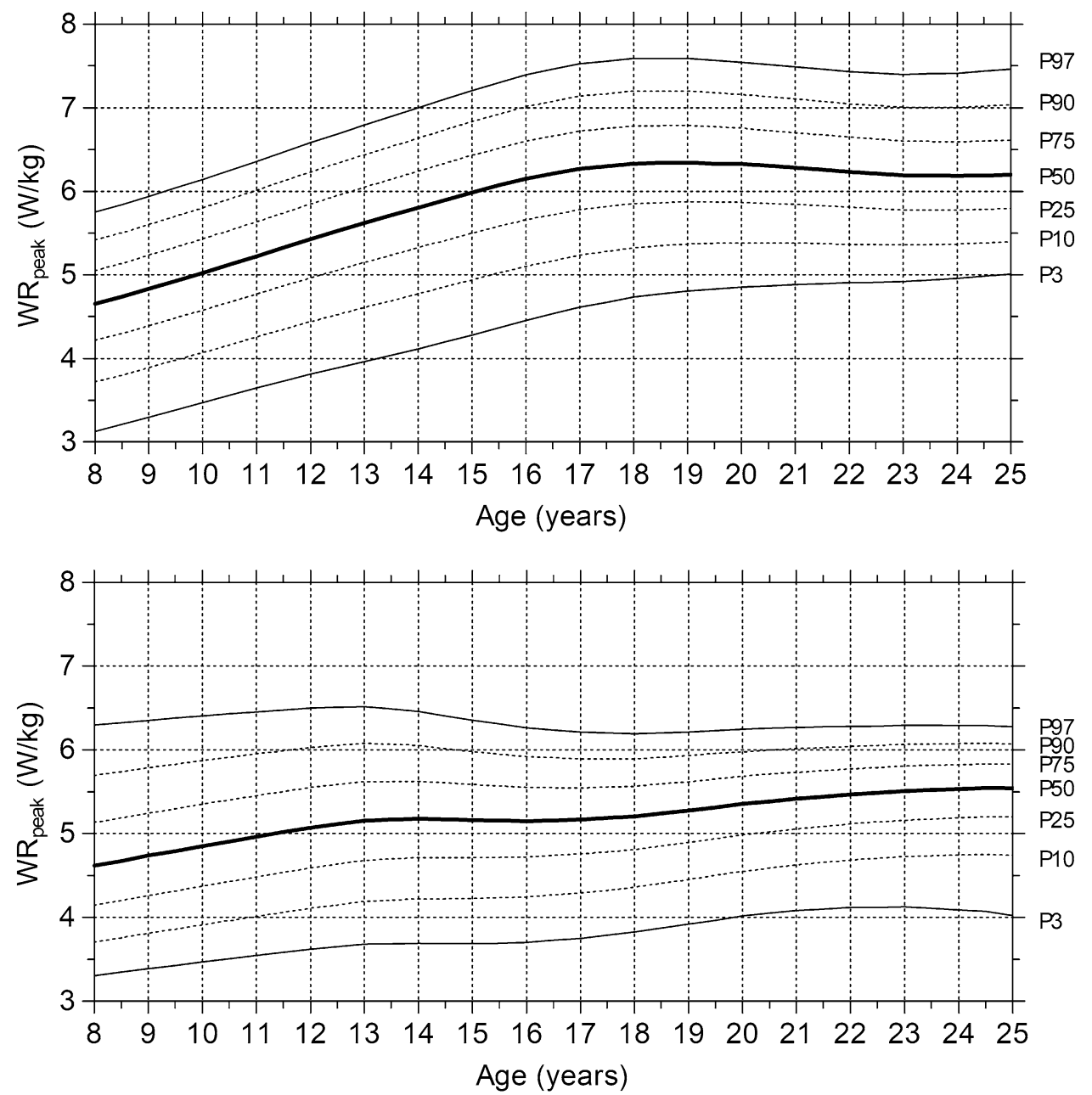

\section{Discussion}

The purpose of this study was to extend the currently available sex- and age-specific normative values and centile curves for SRT performance in 19-24-year-old healthy young adults. This study provides these extended norma-

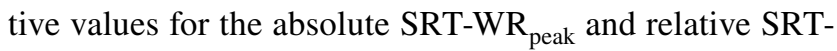
$\mathrm{WR}_{\text {peak }}$ in 19-24-year-old males and females, and combined them with the existing data of 8-19-year-old boys and girls. This provides a complete overview concerning the development of SRT performance throughout childhood into early adulthood.

As expected, peak work rates increased with age in both males and females. This trend continued in males until the age of 24 years, but leveled off after 19 years in females, which is comparable to the Dubowy study in which children and adults show the same curves for absolute $V \mathrm{O}_{2 \text { peak }}$ values attained during an incremental treadmill-based exercise test (Dubowy et al. 2008). It seems that the impact of growth and maturation proceeds in boys and males until 24 years, but becomes less dominant in effect on performance in girls and females after 19 years. This less-dominant impact of growth on SRT performance is confirmed with the lower correlations $(\rho[0.02-0.71])$ of growth-related anthropometric variables in this young adult study population compared to overall strong correlations in the younger ( $<19$ years) population reported by Bongers et al. (2013b). Additionally, SRT performance is suggested to be more prominently limited by the local skeletal muscle anaerobic energy system, which is suggested to contribute much more to the energy supply during the SRT than in the more aerobic considered CPET (Rozenberg et al. 2015) and which is less dependent on growth and maturation. Hence, SRT-WR peak $_{\text {values in }}$ both females and males are much higher than what would be expected at the conventional CPET. As there is a strong positive association between ramp slope and peak power output and a strong negative association between time until exhaustion and peak power output (Morton 2011), the high

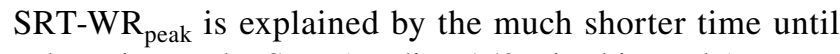
exhaustion at the SRT (median $159 \mathrm{~s}$ in this study) versus the recommended time to induce exhaustion within $10 \mathrm{~min}$ for the conventional CPET (ATS/ACCP 2003). 
Normalized for body mass, a linear increase in relative SRT performance is seen in male subjects until the age of 18 years, whereas a relatively stable trend is observed in female subjects. Again, comparable curves are noted for body mass-corrected "relative" $V \mathrm{O}_{2 \text { peak }}$ values $(\mathrm{ml} / \mathrm{kg} / \mathrm{min})$ in the Dubowy treadmill protocol; however, the plateauphase starts later in boys and males at the age of 24 (Dubowy et al. 2008).

The availability of these extended normative values has two main (clinical) advantages. First, given the reported excellent associations of SRT-WR peak with $V \mathrm{O}_{2 \text { peak }}$ in previous studies (Bongers et al. 2015; Braam et al. 2015; De Backer et al. 2007; Rozenberg et al. 2015; Strookappe et al. 2016; Stuiver et al. 2017), these extended norms provide the clinician with reference values to follow CRF throughout the early (childhood, adolescence, and young adulthood) life-span of an individual during health and disease. This provides the clinician with a tool to initiate interventions as exercise training in time and only when necessary. Additionally, in pediatric chronic diseases which start to manifest in (early) childhood (e.g., asthma, cystic fibrosis, pediatric cardiology, oncology), these norms can be used to adequately follow the development of patients CRF from childhood into early adulthood using the same exercise test and the same set of norm values. Second, these extended SRT norms provide clinicians with an alternative to track $\mathrm{CRF}$ without the necessity for respiratory gas analysis. We advise to base the choice of which reference curves to use on clinical considerations. As the current normative values are presented as body height, body mass, and FFM-specific, reference curves can be used for shorter and taller, as well as for over- and underweight patients.

Additionally, in that way, the SRT can be used as a screening tool for the necessity to perform a standard CPET. As advised by Bongers et al. (2013b), when the absolute SRT-WR peak $_{\text {or relative SRT-WR }}$ peak at a validly performed SRT are below the third percentile for age-, body height- or body mass-related curves, a CPET can be used to differentiate between cardiorespiratory, metabolic, or local skeletal muscle origin of lowered CRF. Being the golden standard for assessment of CRF, measurement of $V_{2} \mathrm{O}_{2 \text { peak }}$ with a CPET should always be the test of choice when used for diagnostic purposes.

Although the SRT is reported to be safe and already part of usual care and regular follow-up in diverse deconditioned patient populations, precautions should be taken to enhance safety during and after testing, especially when performed in the presence of cardiopulmonary disease. Exercise $\mathrm{HR}_{\text {peak }}$ (mean $87 \%$ of predicted $\mathrm{HR}_{\text {peak }}$; $93 \%$ of participants attained $>80 \%$ predicted $\mathrm{HR}_{\text {peak }}$ ) and mean $\mathrm{BP}$ response [mean increase in systolic BP of $49 \pm 19 \mathrm{~mm} \mathrm{Hg}$ (range +3 to $+109 \mathrm{~mm} \mathrm{Hg}$ )] were evident, and were comparable with maximal dynamic cycle ergometry values in elite athletes in which exaggerated BP responses are observed (Pressler et al. 2013). Based on this observation and previously reported (close-to) maximal cardiopulmonary responses $(\sim$ SRT-HR peak $>90 \%$ of CPET-HR peak $)$ induced by the SRT in clinical and healthy populations (Bongers et al. 2013a; Braam et al. 2015; Chura et al. 2012; De Backer et al. 2010; Meyer et al. 1997; Rozenberg et al. 2015; Werkman et al. 2011), the SRT should be regarded as a maximal exercise test (Holland et al. 2014). We advise to monitor HR and BP at rest, at peak exercise, and throughout at least 5 minutes of active and passive recovery. In patients with pulmonary diseases, pulse oximetry can be used to monitor peripheral oxygenation continuously.

One methodological consideration is the possibility of a small selection bias as the main part of the participants were recruited at the University of Applied Sciences, Department of Movement Studies. Participants may therefore be more physically active and more fit than sex- and age-related peers, as well as possibly having a higher socioeconomic status. However, in another part of the STERNUM study, a representative subgroup also performed a CPET, in which their $V \mathrm{O}_{2 \text { peak }}$ was measured as gold standard for CRF. The mean measured $V_{2} \mathrm{O}_{\text {peak }}$ equaled $99 \%$ of predicted [range 74-134\%]) $\left(V \mathrm{O}_{\text {2peak }}\right.$ data from Van de Poppe et al. 2019), indicating that the current study participants are an adequate reflection of the general population considering CRF. Furthermore, general evaluation of the student's background from introduction surveys when subscribing for the Department of Movement Studies reveals that most physical therapy students are the first in the family starting a study in higher education. This suggests that the currently collected normative data are generalizable. However, still, the relatively small sample size contributes to the limitation as it precludes the assumption of a high degree of similarity with the general population which could not be accounted for.

In future, it is of evident clinical necessity to further extend these normative values for healthy elderly to be able to follow CRF in older (chronic) patients were exercise testing is part of usual care. Furthermore, disease-specific norms are necessary.

In conclusion, the present study provides sex-, age-, body height-, body mass-, and FFM-related normative values (presented as reference centiles) for absolute and relative SRT performance throughout childhood and early adulthood. Reference curves for SRT performance show different trends between male and female subjects when modelled against age, body height, and body mass, highlighting the necessity for these normative values to follow CRF easily over time in health and disease.

Acknowledgements We thank Ms. L. Verhoeven, Mr. R. Brouwer, Mr. G. van de Berg, and Mr. M. Joosten (students at the University of Applied Sciences, Department of Movement Studies, Utrecht) for their 
assistance in participants recruitment, planning and testing as part of their bachelor thesis. Special thanks to Mr. J. Pekaric, MSc (head of Expertise Group Cardiopulmonary and Metabolic Diseases, University of Applied Sciences, Department of Movement Studies, Utrecht) and Mr. J. Custers, $\mathrm{PhD}$ (senior lecturer Expertise Group Cardiopulmonary and Metabolic Diseases, University of Applied Sciences, Department of Movement Studies, Utrecht) for supplying MW with the necessary time during the initial phase of the study design.

Author contributions MW, BB and HW conceived and designed research. MW and TB performed measurements. MW, BB and TT analyzed data. MW, BB, TB, TT and HW wrote the manuscript. All authors read and approved the manuscript.

\section{Compliance with ethical standards}

Conflict of interest The authors declare that they have no conflict of interest.

Open Access This article is distributed under the terms of the Creative Commons Attribution 4.0 International License (http://creativeco mmons.org/licenses/by/4.0/), which permits unrestricted use, distribution, and reproduction in any medium, provided you give appropriate credit to the original author(s) and the source, provide a link to the Creative Commons license, and indicate if changes were made.

\section{References}

American Thoracic Society; American College of Chest Physicians (2003) ATS/ACCP Statement on cardiopulmonary exercise testing. Am J Respir Crit Care Med 167(2):211-277

Balady GJ, Chaitman B, Driscoll D et al (1998) Recommendations for cardiovascular screening, staffing, and emergency policies at health/fitness facilities. Circulation 97(22):2283-2293

Bongers BC, de Vries SI, Helders PJ, Takken T (2013a) The steep ramp test in healthy children and adolescents: reliability and validity. Med Sci Sports Exerc 45(2):366-371

Bongers BC, de Vries SI, Obeid J, van Buuren S, Takken T (2013b) The Steep Ramp Test in Dutch white children and adolescents: age- and sex-related normative values. Phys Ther 93:1530-1539

Bongers BC, Werkman MS, Arets HGM, Takken T, Hulzebos HJ (2015) A possible alternative exercise test for youths with cystic fibrosis: the steep ramp test. Med Sci Sports Exerc 47:485-492

Chura RL, Marciniuk DD, Clemens R, Butcher SJ (2012) Test-retest reproducibility and physiological responses associated with the steep ramp anaerobic test in patients with COPD. Pulm Med. https ://doi.org/10.1155/2012/653831

Cole TJ, Green PJ (1992) Smoothing reference centile curves: the LMS method and penalized likelihood. Stat Med 11:1305-1319

De Backer IC, Schep G, Hoogeveen A, Vreugdenhil G, Kester AD, van Breda E (2007) Exercise testing and training in a cancer rehabilitation program: the advantage of the steep ramp test. Arch Phys Med Rehabil 88(5):610-616

Dubowy KO, Baden W, Bernitzki S, Peters B (2008) A practical and transferable new protocol for treadmill testing of children and adults. Cardiol Young 8(6):615-623

Durnin JVGA, Womersley J (1974) Body fat assessed from total body density and its estimation from skinfold thickness measurements of 481 men and women aged from 1672 years. Br J Nutr 32:7797

Haycock GB, Schwartz GJ, Wisotsky DH (1978) Geometric method for measuring body surface area: a height-weight formula validated in infants, children, and adults. J Pediatr 93:62-66
Holland AE, Spruit MA, Troosters T et al (2014) An official European Respiratory Society/American Thoracic Society technical standard: field walking tests in chronic respiratory disease. Eur Respir J 44(6):1428-1446

Meyer K, Samek L, Schwaibold M, Westbrook S, Hajric R, Lehmann M, Essfeld D, Roskamm H (1996) Physical responses to different modes of interval exercise in patients with chronic heart failureapplication to exercise training. Eur Heart J 17(7):1040-1047

Meyer K, Samek L, Schwaibold M et al (1997) Interval training in patients with severe chronic heart failure: analysis and recommendations for exercise procedures. Med Sci Sports Exerc 29(3):306-312

Morton RH (2011) Why peak power is higher at the end of steeper ramps: an explanation based on the "critical power' concept. J Sports Sci 29(3):307-309

Nes BM, Janszky I, Wisløff U, Støylen A, Karlsen T (2013) Age-predicted maximal heart rate in healthy subjects: the HUNT fitness study. Scand J Med Sci Sports 23:697-704

Pressler A, Jähnig A, Halle M, Haller B (2013) Blood pressure response to maximal dynamic exercise testing in an athletic population. $\mathrm{J}$ Hypertens 36(9):1803-1809

Quanjer PH, Tammeling GJ, Cotes JE, Pedersen OF, Peslin R, Yernault J-C (1993) Lung volumes and forced ventilatory flows. Report Working Party Standardization of Lung Function Tests, European Community for Steel and Coal. Official Statement of the European Respiratory Society. Eur Respir J 6(Suppl 16):5-40

Rozenberg R, Bussmann JB, Lesaffre E, Stam HJ, Praet SF (2015) A steep ramp test is valid for estimating maximal power and oxygen uptake during a standard ramp test in type 2 diabetes. Scand J Med Sci Sports 25(5):595-602

Stevens D, Oades PJ, Armstrong N, Williams CA (2010) A survey of exercise testing and training in UK cystic fibrosis clinics. Cyst Fibros 9(5):302-306

Strookappe B, de Vries J, Elfferich M, Kuijpers P, Knevel T, Drent M (2016) Predictors of fatigue in sarcoidosis: the value of exercise testing. Resp Med 116:49-54

Stuiver MM, Kampshoff CS, Persoon S et al (2017) Validation and refinement of prediction models to estimate exercise capacity in cancer survivors using the steep ramp test. Arch Phys Med Rehabil 98(11):2167-2173

Van de Poppe DJ, Hulzebos E, Takken T et al (2019) Reference values for maximum work rate in apparently healthy Dutch/Flemish adults: data from the LowLands fitness registry. Acta Cardiol 74(3):223-230

Vanhees L, Lefevre J, Philippaerts R et al (2005) How to assess physical activity? How to assess physical fitness? Eur J Cardiovasc Prev Rehabil 12(2):102-114

Weggemans RM, Backx FJG, Borghouts L et al (2018) The 2017 Dutch physical activity guidelines. Int J Behav Nutr Phys Act 15(1):58

Weisman M, Beck K, Casaburi R et al (2003) ATS/ACCP statement on cardiopulmonary exercise testing. Am J Resp Crit Care Med 167(2):211-277

Werkman MS, Hulzebos HJ, Van de Weert-van Leeuwen PB, Arets HGM, Helders PJM, Takken T (2011) Supramaximal verification of peak oxygen uptake in adolescents with cystic fibrosis. Pediatr Phys Ther 23:15-21

Publisher's Note Springer Nature remains neutral with regard to jurisdictional claims in published maps and institutional affiliations. 